Mujeres, sociedad y economía de la República del Paraguay

Gabriela Dalla- Corte Caballero

Anuario № 30 / ISSN 1853-8835 / pp. 194-216 /2018

http://anuariodehistoria.unr.edu.ar/ojs/index.php/Anuario/index

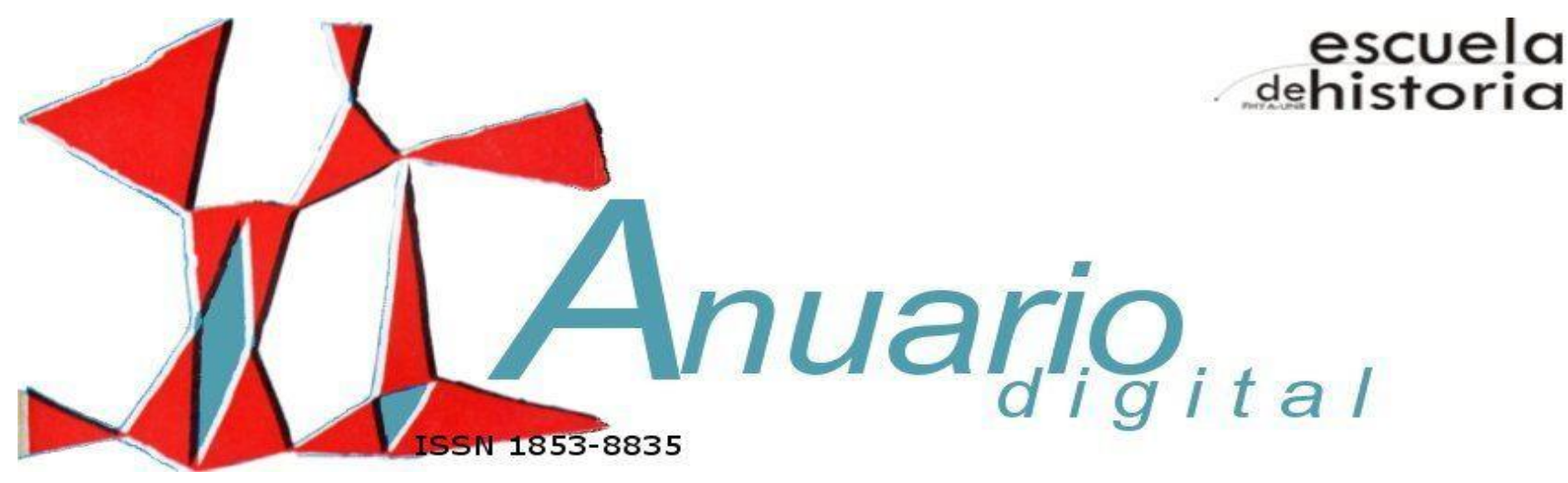

Mujeres, sociedad y economía de la república del Paraguay*

Women, society and economy of the Republic of Paraguay

GABRIELA DALLA- CORTE CABALLERO

(Universitat de Barcelona); España

RESUMEN

Este trabajo tiene como objetivo abordar el rol ejercido por las familias paraguayas encabezadas por mujeres durante la reorganización del país en el periodo de entreguerras. Me refiero al momento histórico que se abre con el fin de la Guerra de la Triple Alianza contra el Paraguay, y que llega a su fin en el momento en que estalla la cruenta Guerra del Chaco, la cual fue disputada entre Paraguay y Bolivia por el control territorial de la zona occidental del país. Los documentos históricos utilizados para elaborar este artículo corresponden a los catálogos de los objetos típicos del Paraguay que su gobierno optó por exhibir públicamente su producción en diversas exposiciones universales organizadas a partir de la década de 1880, en particular la de 1882 en

\footnotetext{
* Este texto fue publicado originalmente en Gabriela Dalla-Corte Caballero -coordinadora y editora-Familias, movilidad y migración en América Latina y España, Prohistoria Ediciones; Rosario; 2015, y se reproduce en esta revista con la autorización de la editorial y de familiares de la autora. Agradecemos a Darío Barriera por proveernos este artículo de Gabriela.

Esta obra está sujeta a la Licencia Reconocimiento-NoComercial-Compartirlgual 4.0 Internacional de Creative Commons. http://creativecommons.org/licenses/by-nc-sa/4.0/ 


\section{MUJERES, SOCIEDAD Y ECONOMÍA DE LA REPÚBLICA DEL PARAGUAY}

Buenos Aires, la de 1885 en Amberes, la de 1888 en Barcelona, y finalmente la de 1889 en París. Estas exposiciones nos permiten comprender el rol ejercido por las mujeres paraguayas a la hora de ofrecer los recursos familiares por ellas conformados.

Palabras clave: Mujeres; Paraguay; entreguerras; catálogos; exposiciones.

\section{ABSTRACT}

This work aims to address the role played by Paraguayan families headed by women during the reorganization of the country in the interwar period. I am referring to the historical moment that begins with the end of the War of the Triple Alliance against Paraguay, and that comes to an end at the moment when the bloody War of the Chaco erupts, which was disputed between Paraguay and Bolivia by the territorial control of the western part of the country. The historical documents used to elaborate this article correspond to the catalogs of the typical objects of Paraguay that his government chose to publicly exhibit its production in various universal exhibitions organized since the 1880s, particularly the one in 1882 in Buenos Aires, the of 1885 in Antwerp, that of 1888 in Barcelona, and finally that of 1889 in Paris. These exhibitions allow us to understand the role exercised by Paraguayan women when it comes to offering the family resources formed by them.

Keywords: Women; Paraguay; interwar; catalogs; exhibitions.

El modelo de expansión productiva y económica implementado desde el año 1851 en Europa fue la exposición de productos producidos por cada país. El caso paradigmático lo ofrece la primera Gran Exposición de los Trabajos de la Industria de todas las Naciones celebrada en el Palacio de Cristal en Hyde Park de la ciudad de Londres, en Reino Unido. A ello se sumó la Exposición Universal organizada en la capital francesa, así como otros eventos similares: la Exposición Universal de Besanzón, Francia, en 1860; Londres en 1862; París en 1867 y 1878; en la ciudad de Córdoba, Argentina, en 1871; en la ciudad francesa de Lyon, en 1872; en Lima, en 1872; en Viena, en 1873. Y no olvidamos la Exposición de Melbourne, Australia, de 1880, o la llamada Exposición Histórico-Americana que se llevó a cabo en el año 1892 en Madrid.

Fue en esa Exposición Universal del año 1867 ejecutada en París cuando el gobierno paraguayo liderado por el mariscal López. Era un momento en que este país rioplatense se encontraba en plena guerra 195

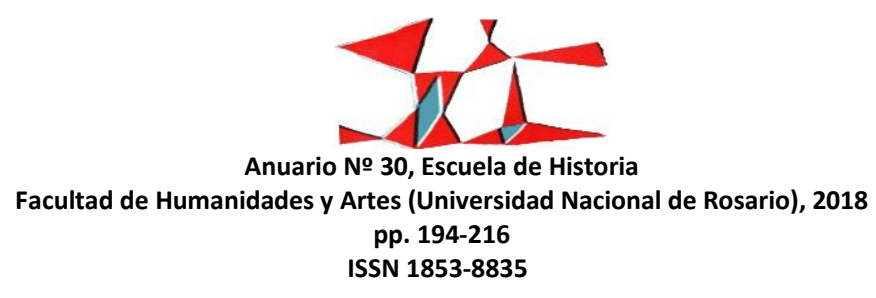


desatada contra los ejércitos de Argentina, Brasil y Uruguay, un conflicto bélico que es conocido hoy día con los nombres de Guerra del Paraguay, o Guerra de la Triple Alianza contra el Paraguay. En dicha exposición las autoridades paraguayas recibieron la medalla de oro por su muestra de maderas, mientras que el empresario M. A. Demersay fue premiado con la medalla de bronce por el tabaco producido en la región oriental del país de lengua guaraní.

Llegada a su fin esa Guerra Grande, ${ }^{1}$ el país vencido, Paraguay, heredó una sociedad civil conformada por mujeres, ancianas y ancianos, niños y niñas. ${ }^{2}$ De acuerdo a las originales aportaciones que oportunamente hizo la historiadora Bárbara Potthast, la relación demográfica entre los sexos resultó profundamente desequilibrada, ya que existía un promedio de cuatro mujeres por cada varón, sumando que en algunos lugares del país llegaban a veinte mujeres. Paraguay se hizo famoso en el mundo como "el país de las mujeres", un término que hizo referencia a la situación demográfica, olvidando por ejemplo los ámbitos políticos, laborales y económicos. ${ }^{3}$

En marzo del año 1886, es decir, quince años después del fin de esta Guerra de la Triple Alianza contra la sociedad paraguaya, el presidente y general Patricio Escobar ordenó a la Oficina de Estadística del Estado que empadronase unos 82 partidos a través de un censo poblacional. En el año 1975 los historiadores Domingo Rivarola y Grazziella Corvalán publicaron una imprescindible obra sobre la situación social y demográfica en la que quedó el Paraguay a partir del año 1870. Los resultados fueron apremiantes ya que faltaba la población masculina de más de 40 años de edad, al compás de la desaparición física de un $80 \%$ de los varones paraguayos. Este texto nos permite agudizar las características de la población paraguaya dividida por sexo y edades, correspondiente a los datos ofrecidos por el censo levantado en 1886 que reproducimos en esta introducción como elemento de reflexión histórica e historiográfica. ${ }^{4}$

\footnotetext{
${ }^{1}$ Brezzo, María Liliana; “Reconstrucción, poder político y revoluciones (1870-1920)”. En: Ignacio Telesca (coordinador); Historia del Paraguay; Taurus; Asunción; 2010; pp. 199-224.

2 Magnaterra, Oscar; La Guerra de la Triple Alianza: desde la diplomacia del Patacón al lenguaje del cañón; Editorial Dunken; Buenos Aires; 2002.

3 Potthast, Bárbara; "La mujer en la historia del Paraguay". En: Ignacio Telesca (coordinador); Historia del Paraguay; Taurus; Asunción; 2010, pp. 317-336.

4 Rivarola, Domingo y Corvalán, Grazziella; La Población del Paraguay; Centro Paraguayo de Estudios Sociológicos; Asunción; 1974; p. 12.
} 


\begin{tabular}{|l|r|r|r|r|r|}
\hline \multicolumn{5}{|c|}{ Estadística de la población de Paraguay en 1886 } \\
\hline Edades & Mujeres & $\%$ & Varones & $\%$ & Total población \\
\hline + de 5 & 20.982 & 50,80 & 20.324 & 49,20 & 41.306 \\
\hline 5 a 9 & 18.186 & 50,08 & 18.127 & 49,92 & 36.313 \\
\hline 10 a 14 & 10.069 & 50,23 & 9.975 & 49,77 & 20.044 \\
\hline 15 a 20 & 13.478 & 55,88 & 10.641 & 44,12 & 24.119 \\
\hline 21 a 30 & 31.900 & 58,55 & 22.586 & 41,45 & 54.486 \\
\hline 31 a 40 & 18.697 & 74,44 & 6.420 & 25,56 & 25.117 \\
\hline 41 a 50 & 12.124 & 77,61 & 3.497 & 22,39 & 15.621 \\
\hline 51 a 70 & 9.284 & 77,78 & 2.652 & 22,22 & 11.936 \\
\hline + de 71 & 2.290 & 78,00 & 646 & 22,00 & 2.936 \\
\hline Total & $\mathbf{1 3 7 . 0 1 0}$ & $\mathbf{5 9 , 0 9}$ & $\mathbf{9 4 . 8 6 8}$ & $\mathbf{4 0 , 9 1}$ & $\mathbf{2 3 1 . 8 7 8}$ \\
\hline
\end{tabular}

Ahora bien: en virtud de la situación económica y social en que quedó su población, Paraguay no pudo participar en las exposiciones organizadas en 1871 en la Provincia de Córdoba de la República Argentina, ni en la que se llevó a cabo en 1872 en la ciudad de Lima, la capital de la República del Perú. Tampoco en el certamen de Santiago de Chile de 1875, ni en la Exposición Universal parisina de 1878. Eran años en que las familias paraguayas intentaban reconstruir un país que sufría grandes limitaciones sociales y económicas, ${ }^{5}$ años en que también fueron vendidas las tierras productivas paraguayas a unas escasas empresas extranjeras. ${ }^{6}$

\footnotetext{
5 Brezzo, Liliana María , Alfredo Boccia Romañach, y Domingo M. Rivarola (editores), Carlos Pastore Goiburu, 65 años de La Lucha por la Tierra en el Paraguay; Centro Paraguayo de Estudios Sociológicos y Academia Paraguaya de la Historia; Asunción; 2014. ${ }^{6}$ Gaylord Warren, Harris; La reconstrucción del Paraguay, 1878-1904; Intercontinental Editora; Asunción; 2010.
}

197

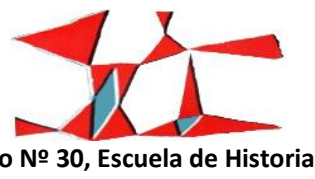


La participación expositiva de la República del Paraguay se detecta recién en la organización de la Exposición Continental Sudamericana que se hizo en el año 1882 en la ciudad de Buenos Aires gracias a la labor ejecutada por el Club Industrial argentino. ${ }^{7}$ A esto se sumó la mención del Paraguay en la Exposición de Amberes de 1885; y en especial su actuación de carácter nacional en dos exposiciones universales que son objeto de este estudio: la de Barcelona de año 1888, y la de París de 1889. El contenido de los catálogos de estas últimas dos exposiciones mencionadas que tuvieron lugar en los años 1888 y 1889, nos muestra a un buen número de mujeres paraguayas que decidieron aportar sus recursos y participar en los mencionados proyectos internacionales. De este modo, en las "mega ferias" en que eran expuestos los grandes avances de la invención tecnológica junto a las últimas expresiones del arte, la cultura y la enseñanza educativa, las mujeres paraguayas contribuyeron con sus creaciones más bien domésticas y personales que hoy día forman parte de los proyectos comerciales basados precisamente en los recursos propios de la tradición femenina paraguaya.

Este artículo tiene como objetivo abordar el rol ejercido por las familias paraguayas encabezadas por mujeres durante la reorganización del país en el periodo de entreguerras. Me refiero al momento histórico que se abre con el fin de la Guerra de la Triple Alianza contra el Paraguay, y que llega a su fin en el momento en que estalla la cruenta Guerra del Chaco, ${ }^{8}$ la cual fue disputada entre Paraguay y Bolivia por el control territorial de la zona occidental del país. ${ }^{9}$ Los documentos históricos utilizados para elaborar este artículo corresponden a los catálogos de los objetos típicos del Paraguay que su gobierno optó por exhibir públicamente su producción en diversas exposiciones universales organizadas a partir de la década de 1880, en particular la de 1882 en Buenos Aires, la de 1885 en Amberes, la de 1888 en Barcelona, y finalmente la de 1889 en París. Estas exposiciones nos permiten comprender el rol ejercido por las mujeres paraguayas a la hora de ofrecer los recursos familiares por ellas conformados.

Para llevar adelante este trabajo, utilizamos la documentación conservada hoy día en el Museo Histórico "Dr. Julio Marc" de Rosario, República Argentina, así como en la Biblioteca Nacional de Catalunya

\footnotetext{
${ }^{7}$ Djendeeredjian, Julio; “En busca de la excelencia. El impacto de la participación en las exposiciones internacionales sobre la producción agropecuaria argentina durante la segunda mitad del siglo XIX”, en: María Silvia Di Liscia y Andrea Lluch (eds.), Argentina en exposición: ferias y exhibiciones durante los siglos XIX y XX; CSIC; Madrid; 2009.

8 Dalla-Corte Caballero, Gabriela; La Guerra del Chaco. Ciudadanía, Estado y Nación en el siglo XX. La crónica fotográfica de Carlos de Sanctis; Prohistoria Ediciones; Rosario; 2010 (libro reeditado por Editorial Intercontinental; Asunción del Paraguay; 2010 y 2015$).$

${ }^{9}$ Scavone Yegro, Ricardo; Las relaciones entre el Paraguay y Bolivia en el siglo XIX; Servilibro; Asunción; 2004.
}

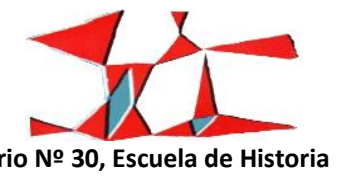




\section{MUJERES, SOCIEDAD Y ECONOMÍA DE LA REPÚBLICA DEL PARAGUAY}

$\overline{\text { (BNC). El primer apartado está dedicado a la Exposición de Buenos Aires de } 1882 \text { y a la de Amberes de 1885; }}$ el segundo apartado a la Exposición Universal de la ciudad de Barcelona de 1888 en la que tuvo una especial actuación el español Matías Alonso Criado; y en el tercero y último apartado, la de París de 1889. Como veremos, desde entonces no hubo actuación femenina en las exposiciones internacionales, tarea asumida estrictamente por empresas y empresarios del Paraguay. En las conclusiones se destaca la participación de las mujeres paraguayas que sobrevivieron a la gran Guerra de la Triple Alianza y llevaron adelante la recuperación del país en el difícil periodo de entreguerras.

\section{Exposición de productos paraguayos: Buenos Aires y Amberes}

En el año 1882 Paraguay participó en la Exposición Continental Sud-Americana que llevaron adelante los empresarios e intelectuales argentinos en el recinto ubicado en la actual Plaza Miserere de la capital argentina ${ }^{10}$ durante el ejercicio de la presidencia de Nicolás Avellaneda. ${ }^{11}$ Paraguay, afectado por la disminución poblacional, lo hizo de manera indirecta, ya que fue el argentino Benigno T. Martínez el responsable de representar a la República paraguaya en este gran proyecto internacional dedicado a reforzar el intercambio comercial y mercantil en el área rioplatense, además de impulsar la organización del Congreso Pedagógico Internacional en el marco de la Exposición Continental de la Industria organizada para los meses de abril y mayo de ese año. ${ }^{12}$

Benigno T. Martínez fue miembro activo de la Sociedad Geográfica Argentina y de la Sociedad "Rivadavia" de la localidad de Mercedes; profesor de historia en el Colegio Nacional y ex-jefe de Estadística General en Montevideo; y cónsul de la República Argentina en la República Oriental del Uruguay. ${ }^{13}$ En ese año 1882, publicó oficialmente en Buenos Aires su interesante folleto titulado "El Paraguay. Memoria bajo el punto de vista industrial y comercial en relación con los países del Plata". En esas páginas presentó el territorio

\footnotetext{
10 Ottone, Eduardo; “Historia de la paleobotánica en la Argentina durante el siglo XIX: científicos, exploradores y el país en exposición". Revista de la Asociación Geológica Argentina; vol. 68, núm. 3; septiembre; Buenos Aires; 2011.

${ }^{11}$ Grassi, Juan Carlos; Una historia del progreso argentino: crónicas ilustradas de las exposiciones y congresos, siglos XIX-XX; Editorial Ferias \& Congresos; Buenos Aires; 2011.

12 Numismática Histórica. Historia Visual; Buenos Aires: Museo Roca; 2012.

13 Berra, Francisco J. A; Agustín de Vedia y Carlos M. de Pena; Álbum de la República Oriental del Uruguay compuesto para la Exposición Continental de Buenos Aires; Imprenta y Encuadernación de Rius y Becchi; Montevideo; 1882.
}

199

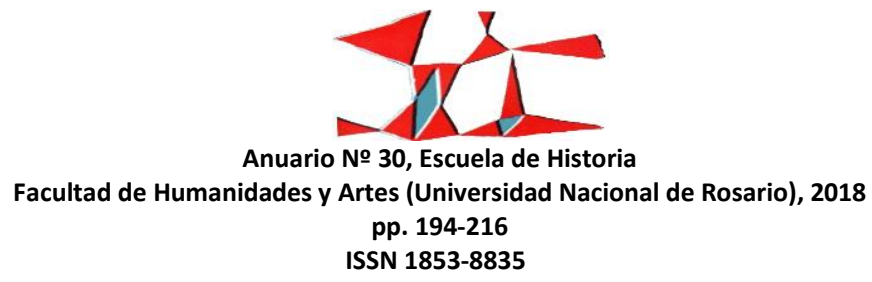


paraguayo como un espacio situado en el centro de la América del Sur, cuya vasta región gozaba de todos los dones y beneficios otorgados por la naturaleza. ${ }^{14}$

Para describir la situación paraguaya, Martínez hizo uso de un escrito que había hecho el alemán Enrique Mageles dos años antes, precisamente en 1880, texto que llegó a sus manos gracias a José Segundo Decoud, el entonces ministro de Relaciones Exteriores de la República del Paraguay. De acuerdo a Mageles, el Paraguay estaba cruzado por caminos carreteros de pueblo a pueblo, pero esos caminos estaban completamente descuidados. Era necesario reorganizar las vías de comunicación fluviales surcadas por un considerable número de buques de vela y a vapor. Ante estas afirmaciones de Mageles, Benigno T. Martínez sostuvo que sus escritos se diferenciaban completamente de las obras anteriores, en particular las del naturalista español y brigadier de la Real Armada, Félix de Azara; ${ }^{15}$ o las de los doctores en medicina y miembros de la Sociedad Helvética de Ciencias Naturales, los suizos Johann Rudolf Rengger, ${ }^{16}$ y Marcelin Lompchamp. ${ }^{17}$

No había dudas, según Martínez, de que ese territorio paraguayo estaba dividido en dos grandes secciones: la del Oriente, que era el Paraguay propiamente dicho; así como la del Occidente, conformada por la vastísima región del Chaco que había sido recientemente adjudicaba a esa República por el presidente de los Estados de Unidos de América, Rutherford Birchard Hayes, en el arbitraje con Argentina. ${ }^{18}$ La superficie del país llegaba en ese momento a 10.000 leguas cuadradas.

Martínez también hizo referencia a otras aportaciones para ampliar los conocimientos sobre la región paraguaya: la del químico y escritor británico Charles Blachford Mansfield, quien publicó en Londres su libro Paraguay, Brasil y la Plata, con descripciones de la sociedad, de los paisajes, plantas y aves, y un esquema sobre la posible colonización del Gran Chaco. ${ }^{19}$ Los textos del comerciante, financista y escritor británico Juan

\footnotetext{
${ }^{14}$ Martínez, Benigno T.; El Paraguay. Memoria bajo el punto de vista industrial y comercial en relación con los países del Plata, Exposición Continental de Buenos Aires; Establecimiento Tipográfico; Buenos Aires; 1882; p. 3.

15 Félix de Azara, Descripción e Historia del Paraguay y del Río de la Plata. Madrid: Imprenta de Sanchiz, 1847.

16 Johann Rudolf Rengger, Viaje al Paraguay en los años 1818 a 1826. Asunción: Tiempos de Historia, 2010 (traducido al castellano, prologado y comentado por Alfredo Tomasini y José Braunstein)

17 Rengger ,Johann Rudolf y Marcelin Lompchamp; Ensayo histórico sobre la revolución del Paraguay, y el Gobierno Dictatorio del Dr. Francia; Imprenta de Moreau; París; 1928 (traducido al castellano por D. J. C. Pagès, intérprete real).

18 Brezzo, Liliana María; “La guerra de la Triple Alianza en los límites de la ortodoxia: mitos y tabúes”; Revista Universum, № 19, vol.

1; Universidad de Talca; 2004; pp. 10-27.

${ }^{19}$ Blachford Mansfield, Charles; Paraguay, Brasil y la Plata; Londres; Kingsley; 1856.
}

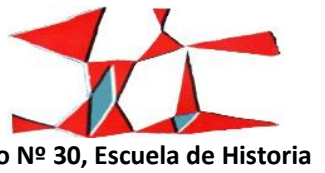




\section{MUJERES, SOCIEDAD Y ECONOMÍA DE LA REPÚBLICA DEL PARAGUAY}

Parish Robertson, ${ }^{20}$ quien había participado en los eventos independentistas rioplatenses. El libro que Thomas Jefferson Page dio a conocer en Londres por su visita política y comercial al sur de América titulado El Río de la Plata, la Confederación Argentina y Paraguay. ${ }^{21} \mathrm{O}$ el francés Alfred Demersay y Methfessel, quien visitó Paraguay antes de la Guerra de la Triple Alianza, ${ }^{22}$ y quien elaboró un libro sobre economía, política y geografía del Paraguay. ${ }^{23}$

Mencionamos también la obra del naturalista francés Martin de Moussy sobre la geografía; ${ }^{24}$ así como Marbais du Graty, quien en 1865 había dado a la luz su libro La République du Paraguay. ${ }^{25}$ Du Graty había aportado su breve catálogo incluyendo los nombres vulgares con que se conocían los árboles, arbustos y plantas paraguayas. Según él, se trataba de una imprescindible contribución sobre las observaciones meteorológicas del Paraguay, y sus posibles aplicaciones agrícolas e industriales dedicadas a la exportación, tema central para el propio Benigno T. Martínez que expresó en su libro titulado El Paraguay. Memoria bajo el punto de vista industrial y comercial en relación con los países del Plata. En él mencionó también los recursos naturales que podían utilizarse en Paraguay, señalando que a este país le faltaban 300.000 inmigrantes, así como el aprovechamiento de sus recursos, como el hierro, el cobre, el manganeso, la piedra, el oro, y en especial, la riqueza del suelo paraguayo representada por la producción del reino vegetal y por los bosques ricos en maderas. La aplicación de la madera, afirmó, era la base de las construcciones navales, civiles e industriales. Junto a la madera, la fauna paraguaya, los árboles frutales, así como los principales cultivos: tabaco, maíz, trigo, mandioca, caña de azúcar, algodón y arroz. Por ello este cónsul argentino en la República Oriental del Uruguay inició su folleto elaborado para la Exposición Continental Sudamericana de 1882 con la siguiente frase: "Ia Guerra del Paraguay contra los Aliados produjo consiguientemente la ruina de todo". 26

\footnotetext{
20 Parish Robertson, John; Letters on South America; John Murray-Albemarle Street; Londres; 1843.

21 Jefferson Page Thomas; El Río de la Plata, la Confederación Argentina y Paraguay; Intercontinental Ediciones; Asunción; 2007.

22 Demersay, Alfred; Une Mission géographique dans les archives d'Esagne et de Portugal: 1862-1863. París: L. Hachette, 1864.

${ }^{23}$ Demersay, Alfred; Histoire Physique, Económica y Politique Du Paraguay Et Des Etablissements Des Jesuites, s/d, 1862.

${ }^{24}$ Martin de Moussy, Jean Antoine Victor de; Description Géographique et Statistique de la Confédération Argentine. París: Librerie Firmín Didot; 1860; 2 tomos.

${ }^{25}$ Alfred Louis Huert Ghislain Marbais du Graty, barón, La République du Paraguay; Bruxelles, Leipzig, Gand; Librairie Européenne de

C. Muquardt; 1865.

26 Martínez, Benigno T.; El Paraguay...; 1882; pp. 10-11.
}

201

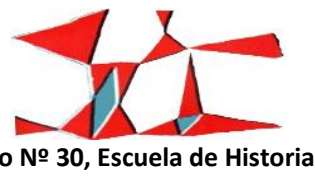

Facultad de Humanidades y Artes (Universidad Nacional de Rosario), 2018

pp. 194-216

ISSN 1853-8835 
Las mujeres paraguayas se habían volcado a elaborar cigarros y a producir todo tipo de recursos agrícolas para sobrevivir, y para llevar adelante la supervivencia de sus hijos e hijas. Esas mujeres, según Martínez, "han quedado en mucho mayor número que los hombres con motivo de la guerra", y por ello en ese año 1882 utilizó los datos de Enrique Mageles aportados por Decoud para señalar las 180.301 hectáreas cubiertas por los siguientes productos en manos básicamente femeninas: 84.041 hectáreas de maíz, trigo y cebada; 50.280 de mandioca; 16.600 de tabaco; 9.380 de caña de azúcar; 20.000 para algodón y otros productos. Por ello la única solución que encontró Martínez ante la disminuida producción agrícola fue la de educar a las familias paraguaya para que aprendiesen a cultivar, siguiendo un sistema de modernización que sólo podía imponer un departamento de agricultura similar al que ya existía en Argentina y en los Estados Unidos de América:

"El agricultor paraguayo se limita a plantar una cantidad muy reducida, y cada año siembra exactamente igual al anterior. Con este sistema no es posible concebir progreso alguno. Para combatir esta indolencia característica de nuestra raza, hay dos medios: la persuasión y el estímulo. Las autoridades de la campaña deben recomendar a los vecinos de sus municipios que traten de aumentar sus plantaciones. El Gobierno, por su parte, debe estimular a los agricultores, estableciendo precios diversos para aquellos que hayan cosechado cierta cantidad de tabaco, algodón, caña de azúcar, café, arroz, maíz, etc... La creación de un Departamento de Agricultura como el que existe en los Estados Unidos, en la República Argentina, y en casi todos los países de Europa, sería de trascendental importancia para el fomento de esta industria". ${ }^{27}$

Martínez defendió especialmente la producción de la yerba mate y del tabaco. A esto se sumó la necesidad de incorporar familias de inmigrantes procedentes de Europa: siguiendo el folleto de José Segundo Decoud ${ }^{28}$ el personaje que venimos analizando afirmó ante los lectores de la Exposición porteña que el aumento de las riquezas públicas paraguayas dependía especialmente del incremento de su población. De ahí la urgencia de dictar una ley de colonización de sus territorios fértiles y desiertos: decidió reproducir el mensaje del General Bernardino Caballero durante el acto de apertura de las sesiones del Congreso de abril de 1881. Caballero había accedido a la presidencia provisoria del Paraguay en setiembre de 1880, y en el

\footnotetext{
27 Ibídem; pp. 22-24.

28 Decoud, José Segundo; Cuestiones políticas y económica; s/d; Asunción; 1877.

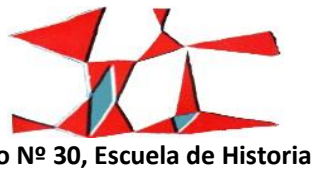




\section{MUJERES, SOCIEDAD Y ECONOMÍA DE LA REPÚBLICA DEL PARAGUAY}

mencionado discurso afirmó que "tenemos necesidad de amentar nuestra población por medios artificiales, concediendo liberalmente al colono que venga a establecerse aquí tierras y las mismas ventajas que se le acuerdan en otras partes" ${ }^{29}$

También transcribió el contenido de la Ley de junio de 1881 que había sido aprobada por el gabinete paraguayo, a cuyo frente se hallaba el General Bernardino Caballero: la mencionada ley había sido diseñada por el Departamento General de Inmigración bajo dependencia del Ministerio del Interior, y que acompañaba a la Ley de tierras públicas que se había volcado a la captación de inmigrantes ofreciéndoles terreno sin gravamen alguno. Todos estos datos no eran casuales ya que la comisión organizadora de la Exposición Continental de Buenos Aires otorgó una medalla de oro a Thomas Larangeira por la yerba mate; una medalla de plata a Van Strate por sus diversos licores; así como otra medalla de plata para Rafael Augusti por la yerba mate que era elaborada en sus establecimientos ubicados en la zona oriental del Paraguay.

A partir de su contribución en la Exposición de 1882, Martínez elaboró textos dedicados a la historia regional de la Provincia de Entre Ríos, ${ }^{30}$ así como a la historia contemporánea de la República Argentina, reforzando de esta manera su interés por la cercanía entre modernización e industrialización de los territorios paraguayos, uruguayos y argentinos. Editó un diccionario que incluyó a los escritores nacidos en Hispanoamérica, ${ }^{31}$ además de publicar numerosos libros de lecciones de enseñanza de geografía e historia argentina que eran arreglados para el uso de los colegios nacionales, escuelas normales y escuelas comunes. ${ }^{32}$

A la Exposición Continental Sud-Americana de Buenos Aires de 1882, le siguió la Exposición Universal de 1885 que se hizo en Amberes, la segunda ciudad en importancia de Bélgica, durante la cual fueron premiados diversos productores de tabaco, yerba mate, licores, cereales, y especialmente los dedicados a la miel de caña de azúcar para elaborar aguardiente, la bebida alcohólica propiamente paraguaya que ya era fabricada, fermentada y destilada en tiempos de los jesuitas. En este acto público el cónsul de Paraguay en Amberes, H. Oostendorp, contribuyó con diversos textos bibliográficos sobre la nueva legislación paraguaya

\footnotetext{
${ }^{29}$ Martínez, Benigno T.;El Paraguay...; p. 68.

30 Martínez, Benigno T.; Historia de la provincia de Entre Ríos; Rosso; Entre Ríos; 1910.

${ }^{31}$ Martínez, Benigno T.; Diccionario biográfico-bibliográfico: de escritores antiguos y modernos nacidos en los países del habla castellana; Imprenta, Litografía y Encuadernación de Stiller y Laass; Buenos Aires; 1886.

32 Martínez, Benigno T.; Curso elemental de historia argentina: segundo curso, que abarca desde 1808 hasta nuestros días; Pedro Igón; Buenos Aires; 1891.
}

203

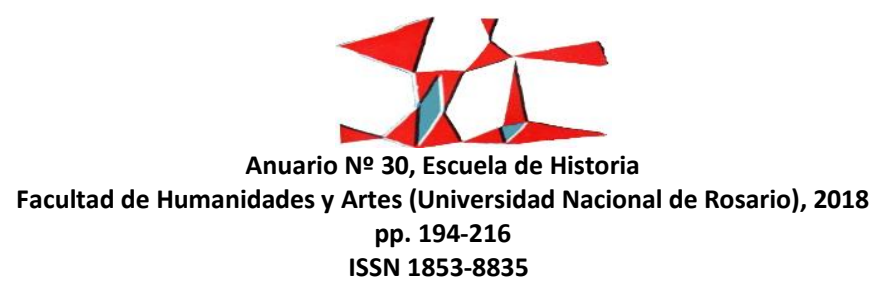


elaborada a partir de los Tratados de Paz firmados con los gobiernos de Argentina y Brasil. Y el propio Gobierno de Paraguay recibió la medalla de oro y la medalla de plata por el impulso otorgado a la explotación de industrias forestales. Los catálogos de la época identifican la entrega del diploma de honor para el ministro de Relaciones Exteriores del Paraguay, junto a diversos premios y menciones otorgados a empresarios y empresarias paraguayos. En el caso de las medallas de oro, al Gobierno de Paraguay por la explotación de madera a través de las industrias forestales, por el tabaco y la yerba mate, y a Thomas Larangeira por la yerba de Villa Concepción.

En relación a las medallas de plata, fueron otorgadas al Gobierno de Paraguay por la concesión de cartas geográficas y productos agrícolas alimenticios; a los encajes de M. Roque de la familia Gonzáles; a los productos químicos y farmacéuticos de Louis Raberty; a los licores de la ciudad de Asunción de J. E. de Guanes; a la caña de azúcar de Luis Rabery; y a la yerba mate de Rafael Augusti. Las medallas de bronce fueron para artículos de exportación, productos agrícolas alimentarios, cereales, azúcar y miel entregados por el Gobierno de Paraguay; aceites y grasas asunceñas de E. J. Mendiondou; licores de Luis Rabery; confituras de la Sra. De Yturburu; caña de azúcar de R. C. Gardner; bibliografía de legislación que entregó el cónsul H. Oostendorp; así como los productos de perfumería de M. Laguardia. Finalmente, la mención honorable fue recibida por el Gobierno de Paraguay por cerámicas, ropa para los dos sexos, minería, cueros y pieles, caña de azúcar y cafés; a "Bertrand \& Cía.", J. Mitjats y L. N. Papalucas por la producción y exportación de cigarrillos y cigarros desde Asunción; las fotografías aportadas por N. Perestrella Da Cámara; productos químicos, farmacéuticos, aguardiente de la caña de azúcar y licores de "Ernesto Grühn \& Cía.", "Boussiron \& Rabery”, "Alfaro \& Cía." y de "M. Decoud".

\section{La Exposición Universal de Barcelona: las mujeres paraguayas}

En 1888 se llevó a cabo en la ciudad de Barcelona la Exposición Universal en el Parque de la Ciudadela, un ámbito anteriormente perteneciente al ejército, y que fue incorporado a la ciudad en el año 1851. Como ocurrió con el diseño del espacio del Fórum en el siglo XX, las obras de la exposición de 1888 permitieron la rehabilitación de la zona del barrio de la Ribera que había servido hasta entonces a las fuerzas militares para oprimir al pueblo barcelonés. El incentivo de los actos feriales conllevó la mejora de las infraestructuras de toda la ciudad condal, que dio un enorme salto hacia la modernización, el desarrollo y las visitas turísticas y culturales. Este accionar supuso el banco de pruebas de un nuevo estilo artístico llamado "modernismo" que 


\section{MUJERES, SOCIEDAD Y ECONOMÍA DE LA REPÚBLICA DEL PARAGUAY}

imperó hasta inicios del siglo XX en el marco de las nuevas construcciones urbanas en manos de la burguesía catalana.

En esta muestra catalana participó el Gobierno de la República del Paraguay, ya que Matías Alonso Criado, español republicano exiliado en la ciudad de Montevideo desde el año 1873, fue nombrado cónsul de Paraguay en España en ese mismo año, ${ }^{33}$ con la orden de impulsar la llegada a la ciudad condal de un importante número de productos elaborados por las mujeres paraguayas, la divulgación del exótico quebracho del Gran Chaco y de la yerba mate que debía ser expuesta ante los fabricantes europeos.

Fue en ese año 1888 cuando Matías Alonso Criado publicó en Montevideo su obra titulada Historia y Geografía del Paraguay, ${ }^{34}$ que fue reeditada en Barcelona por el Establecimiento Tipográfico de los "Sucesores de N. Ramírez y Cía." con el título Descripción estadística-geográfica e histórica del Estado Paraguayo, incluyendo el plano de Asunción y un croquis ilustrado del Río de la Plata. Este texto apareció finalmente en el álbum La Exposición. ${ }^{35}$ En sus discursos presentados ante la Exposición Universal barcelonesa, este cónsul defendió especialmente la venta de las extensas tierras del Chaco Boreal, reconociendo que la Guerra de la Triple Alianza había generado la pérdida de nueve décimas partes de la población del Paraguay, es decir, algo así como un millón de personas fallecidas por la lucha bélica, las epidemias, el hambre y el ostracismo. En ese año 1888, Paraguay se aproximaba a sólo medio millón de habitantes por el fallecimiento del $80 \%$ de la población masculina adulta.

Gran parte de los recursos naturales que llegaron para la Exposición de Barcelona habían sido registrados por los comerciantes y los empresarios extranjeros establecidos en las tierras paraguayas, entre ellos el palentino Carlos Casado del Alisal que lideraba su empresa "Compañía de Tierras Hispano-Paraguaya Limitada" dedicada a la producción de extracto tánico del quebracho colorado en el Chaco paraguayo. Esta enorme zona territorial chaqueña formó parte de las antiguas posesiones españolas, pero era la menos

\footnotetext{
${ }^{33}$ Alonso Criado, Matías; "Prólogo", en Luis Valls y Jaime Moragues; Los españoles del Uruguay; Tipografía Moderna; Montevideo; 1918.

${ }^{34}$ Alonso Criado, Matías; La República del Paraguay; A. Godel; Montevideo; 1888.

35 Alonso Criado, Matías ; “Descripción estadística-geográfica e histórica del Estado Paraguayo, con plano de la Asunción, y un croquis ilustrado del Río de la Plata", en La Exposición, Órgano Oficial de la Exposición Universal de Barcelona, Oficinas de la Exposición Universal; Establecimiento Tipográfico de los Sucesores de N. Ramírez y Cía.; Barcelona; 1886-1889.
}

205

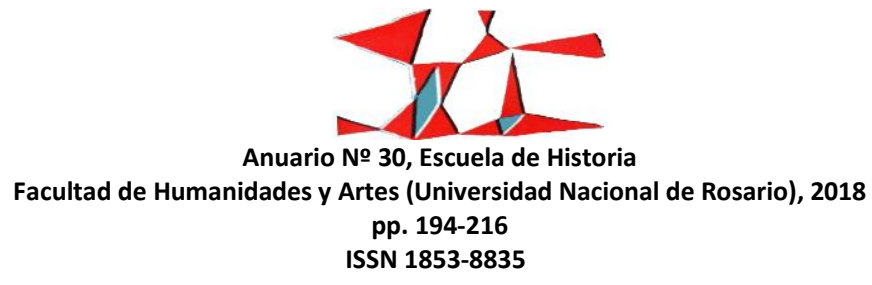


conocida. Tras la guerra, quedó en manos españolas, argentinas, alemanas, inglesas y francesas, y posteriormente, estadounidenses, ${ }^{36}$ países que asumieron roles divergentes. ${ }^{37}$

Alonso Criado defendió especialmente el proyecto de Casado del Alisal de adquirir las tierras chaqueñas y llamar esa extensa propiedad con el nombre de "Nueva España". ${ }^{38}$ La empresa fue rebautizada en el año 1909 con el nombre de "S. A. Carlos Casado, Compañía Limitada de Tierras", tierras en las que se produciría décadas después la Guerra del Chaco entre Paraguay y Bolivia (1932-1935). ${ }^{39}$ La Compañía Trasatlántica española se hizo cargo de trasladar los recursos y objetos del Paraguay hacia el puerto de Barcelona, donde desembarcaron 17 cajas de armas y útiles pertenecientes a los llamados "indígenas guaraníes" de la "raza india"; 407 ejemplares de diferentes mamíferos, aves y culebras, reptiles, peces y moluscos; 107 de plantas medicinales; 14 de plantas textiles; 11 de comestibles; 13 ejemplares tintóreas y 5 de minerales; 16 productos químicos; y a nivel forestal, 104 ejemplares de la vegetación paraguaya. También llegaron 37 tejidos especiales del país, así como pieles naturales y curtidas que según Matías Alonso hacían honor a la habilidad y a la laboriosidad de las mujeres del Paraguay. Por su calidad de abogado, médico, escritor y agrónomo, Alonso Criado difundió también los productos elaborados por las mujeres paraguayas, en particular los objetos artísticos. La Comisión encargada de llevar adelante esta exposición señaló precisamente que la ciudad de Asunción había quedado en su totalidad en manos de mujeres. ${ }^{41}$

A la hora de que la Exposición Universal barcelonesa reconociese la colaboración de Alonso Criado, este último recibió una medalla de oro por el mapa que hizo de la República del Paraguay, señalando en su documento las maderas más importantes y útiles: peterebí, urundey, tatayiba, ibaró, palo-lanza, ibirá, ibirá-

\footnotetext{
36 J. G. I. "Nuestras relaciones con las Repúblicas Hispano-Americanas. Instalaciones del Uruguay, Paraguay, Chile, Ecuador, Bolivia, Honduras y la República Argentina. Conclusión", en Algunas noticias sobre la Exposición Universal de Barcelona en 1888, por la Comisión Hidrográfica de la Península, publicado en la Revista General de Marina; Establecimiento Tipográfico de Fortanet, Impresor de la Real Academia de la Historia; Madrid; 1888; pp. 148-160.

37 Maria Fradera, Josep; La nación imperial. Derechos, representación y ciudadanía en los imperios de Gran Bretaña, Francia, España y Estados Unidos (1750-1918); Edhasa; Barcelona; 2015.

${ }^{38}$ Dalla-Corte Caballero, Gabriela; Empresas y tierras de Carlos Casado en el Chaco Paraguayo. Historias, negocios y guerras (18601940); Intercontinental Editora; Asunción; 2012.

39 Dalla-Corte Caballero, Gabriela; "Extranjeros en el Paraguay de entreguerras. Actores y disputas en el proyecto nacional en el Chaco Boreal”, en Evelyne Sanchez (coord.), Actores locales de la nación en América Latina. Estudios estratégicos; Benemérita Universidad Autónoma de Puebla, El Colegio de Tlaxcala, A.C. México; 2011; pp. 201-236.

40 Zanardini, José; "La Lucha por la Tierra de los Pueblos Indígenas", en Liliana María Brezzo et al. (eds.), Carlos Pastore Goiburu, 65 años de La Lucha por la Tierra en el Paraguay; Centro Paraguayo de Estudios Sociológicos y Academia Paraguaya de la Historia; Asunción; 2014; pp. 251-263.
}

41 J. G. I. "Nuestras relaciones..."; pp. 153-155.

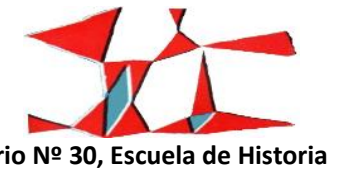

Facultad de Humanidades y Artes (Universidad Nacional de Rosario), 2018

pp. 194-216

ISSN 1853-8835 


\section{MUJERES, SOCIEDAD Y ECONOMÍA DE LA REPÚBLICA DEL PARAGUAY}

pitá, tayi, jacarandá, palo blanco, tatayiba, ${ }^{42}$ querandí, timbó, guayaibí, guayacan, tataré, cedro, y especialmente el quebracho colorado. En relación a los extractos secos de la madera, aportó los provenientes del árbol de compay, tuyuyà pulverizada, y palo santo en polvo. Y estas medallas de oro se repartieron también entre el Gobierno de Paraguay por plantas, maderas, plantas tintóreas, yerba mate, tabacos en hojas, extracto seco de maderas, zapallo colorante, maní blanco y negro y semillas de algodón; Ricardo Méndez por maderas; Rafael Augusti y Thomas Larangeira por la yerba mate; y "Pecci Hermanos y Cía." por los vinos amargos y las pastas alimenticias.

Las medallas de plata quedaron en manos de productores de café (Agustín Cañete), licores (Luis Bregains), plantas medicinales (Gobierno de Paraguay), y coleccionistas de bastones (Ildefonso Benegas). Las medallas de bronce, por su parte fueron repartidas entre un elevado número de mujeres paraguayas que elaboraron originales encajes, bordados a mano, almohadas, pañuelos: mencionamos especialmente a las mujeres Petrona Acosta de Talavera, Lorenza Céspedes, Carmen Gill de Cordal, Elvira Gill, Concepción Gill, Dolores Pedroso, Martina Rivarola, Benita Villalba, Petrona Acosta de Talavera, la viuda Victoria de González y Rosalía Domeque. Las hamacas en cuerdas eran elaboradas por Pilar Saucedo, mientras L. Kégel se encargaba de diversos extractos utilizados en Paraguay. También recibió medallas de bronce el Gobierno de Paraguay por cueros, pieles y manufacturas de cabello; Lucas Papalucas, la fábrica "Brumbilla y López", José Mitjants y Antonio Pirès por el tabaco; y Miguel Laguardia por la perfumería.

La mención honorable tuvo otros destinatarios: el Gobierno del Paraguay por la manufactura; la Comisión del Paraguay por los cueros de animales; Marcos Cuarranto por el surtido de fideos; Mac Donell por los rodillos de goma del caucho; Francisco Sáenz Valiente y Eduardo Brugada por la caña de azúcar; Enrique Paganini por el extracto tánico del quebracho; “Fernando Sagnier \& Cía." por harina y fábrica de propiedad; y en especial a las siguientes mujeres paraguayas por su lencería fina y sus bordados a mano: Dolores Pedroso, Juana Rius, Dolores Recalde, Francisca Trigo, Rosario Solalinde, Encarnación Silva, la viuda Victoria de González, y Machaín de Cartabio. El proyecto de exponer diversos productos paraguayos en España fue apoyado por el presidente de la República del Paraguay, el General Patricio Escobar. Junto a él actuaron los

\footnotetext{
42 Colmeiro, Miguel; Diccionario de diversos nombres vulgares de muchas plantas usuales y notables del antiguo y nuevo mundo, con la correspondencia científica y la indicación abreviada de los usos e igualmente de la familia a que pertenece cada planta.

Complemento del curso de Botánica; Imprenta de Gabriel Alhambra; Madrid; 1871; p. 179.
}

207

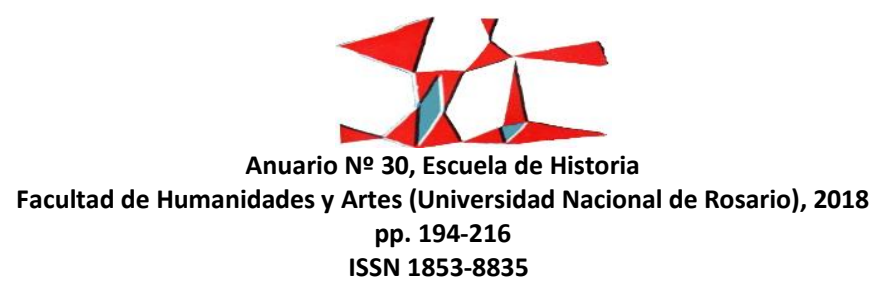


ministros José S. Decoud (Relaciones Exteriores), M. A. Maciel (Justicia, Culto e Instrucción Pública), Juan A. Meza (Interior), Higinio Uriarte (Hacienda) y Pedro Duarte (Guerra), quienes se encargaron de hacer llegar a Barcelona los recursos mencionados.

En síntesis, la contribución que hizo Matías Alonso Criado fue hacer llegar a Barcelona los objetos paraguayos exhibidos durante la Exposición Universal. También favoreció la edición de un catálogo a través de la Imprenta de los Sucesores de N. Ramírez y Cía. que por entonces estaba ubicada en el Pasaje de Escudillers № $4 .{ }^{43}$ Tiempo después el Congreso y el Senado de España nombraron a Matías Alonso Criado como "hijo adoptivo y ciudadano honorario" del Paraguay. Su fallecimiento se produjo en la ciudad de Montevideo el 19 de noviembre de 1922. Reproducimos el mapa del republicano Alonso Criado en el cual es posible identificar el plano de la Villa de Asunción, y la zona del Chaco Boreal como parte de la República del Paraguay. ${ }^{44}$

No es vano mencionar este caso histórico: como hemos demostrado en un trabajo anterior, Matías Alonso Criado fue uno de los consejeros más importantes de la familia Casado-Sastre cuya fábrica llamada “Compañía de Tierras Hispano-Paraguaya Limitada” fundada en la ciudad de Rosario de la República Argentina, se dedicó siempre a la explotación de la madera y del extracto tánico del árbol de quebracho del Gran Chaco latinoamericano. Esta empresa fue establecida en la zona chaqueña paraguaya en el año 1889, gracias a la inauguración del gran Puerto Casado -así llamado en honor a Carlos Casado del Alisal- en la zona occidental del río Paraguay. Matías Alonso Criado participó activamente en este acto público, y lo hizo después de cumplir con la tarea de divulgar los recursos paraguayos durante la Exposición Universal de Barcelona. En ese año 1889 acompañó a los Casado-Sastre en su viaje en barco iniciado en la zona del río Paraná, y les propuso bautizar sus tierras chaqueñas en manos paraguayas con el nombre de “Nueva España”. El republicano español Matías Alonso Criado falleció en la ciudad de Montevideo en el año $1922 .{ }^{45}$

43 Comisión Paraguaya de la Exposición Universal de Barcelona, Catálogo de los objetos que la República del Paraguay exhibe en la Exposición Universal de Barcelona; Imprenta de los Sucesores de N. Ramírez y Cía.; Barcelona; 1888; pp. 45-66.

${ }^{44}$ Alonso Criado, Matías; La Rèpublique du Paraguay, Consul Général de Paraguay en Espagne, traducido del español con permiso del autor por Max Winsweiler, Cónsul General de Paraguay en Francia; R. Coussau \& F. Coustalat, Imprimeurs-Éditeurs; Bordeaux; 1889.

45 Dalla-Corte Caballero, GabrielaM "Las tierras del Chaco Paraguayo, entre Carlos Casado, Matías Alonso Criado y Carlos Pastore”, en Liliana María Brezzo et al (ed.), Carlos Pastore Goiburu, 65 años de La Lucha por la Tierra en el Paraguay; Centro Paraguayo de Estudios Sociológicos y Academia Paraguaya de la Historia; Asunción; 2014; pp. 153-205.

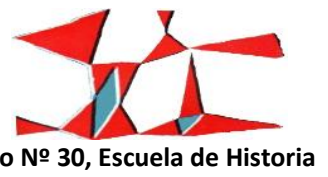




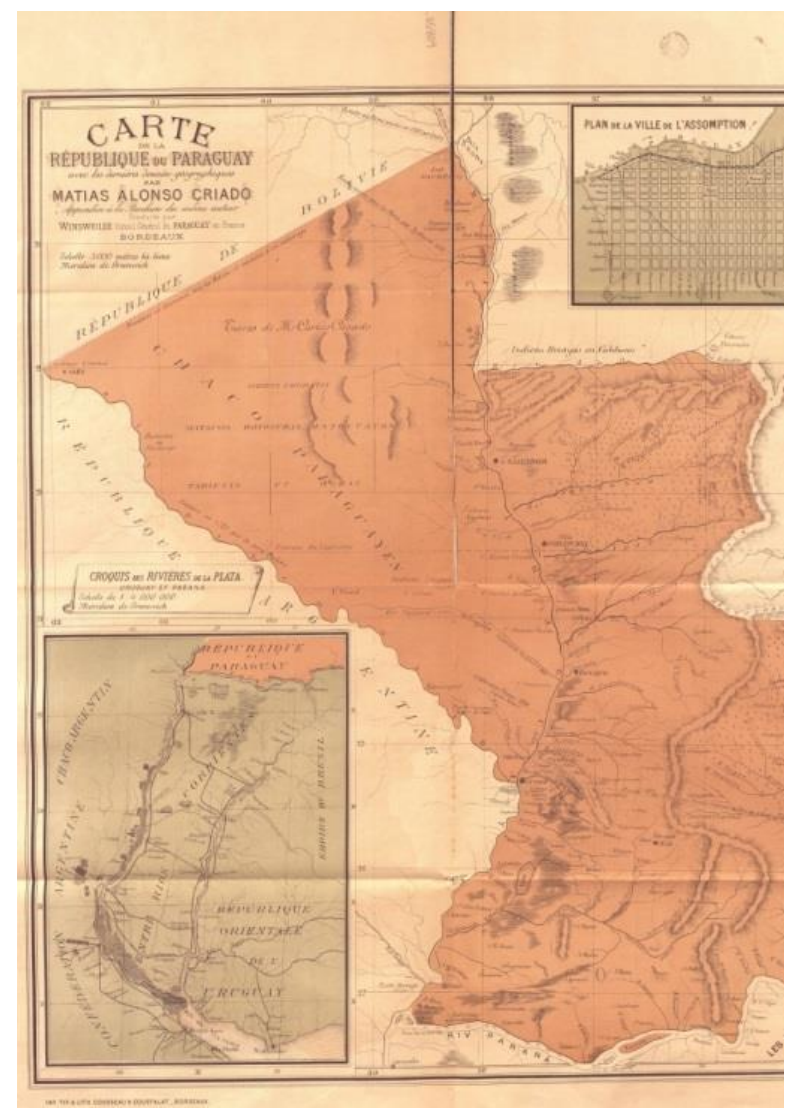

Imagen 1:

Mapa de la República del Paraguay, elaborado por Matías Alonso Criado, cónsul general del Paraguay en España.

Presentado en la Exposición Universal de Barcelona, 1888.

\section{Las mujeres paraguayas y la Exposición Universal de París}

El proyecto expositivo diseñado por la ciudad de Barcelona se amplió cuando París organizó al año siguiente, en 1889, su propia Exposición Universal. Allí fue utilizado el arco de entrada de la Torre Eiffel como símbolo de la feria. La República del Paraguay volvió a figurar en los catálogos franceses. Esta documentación permite identificar la actuación ejercida por los miembros del Gobierno de Paraguay presididos por el General Patricio Escobar: el vicepresidente J. del R. Miranda; y los ministros Coronel Juan C. Centurión, Coronel M. A. Maciel, Coronel Juan A. Meza, General Pedro Duarte y Higinio Uriarte.

La Exposición Universal parisina fue abierta al público durante la celebración del centenario de la toma de la Bastilla y el comienzo de la Revolución Francesa, a través de la inauguración de la Torre Eiffel y de

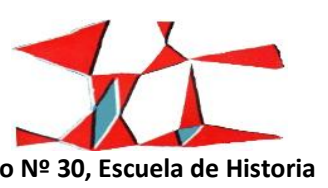


la Galería de Máquinas. ${ }^{46}$ El Gobierno paraguayo apoyó la constitución de una interesante Comisión de Paraguay que se hiciese cargo de la participación en la Exposición Universal de París de 1889. La Exposición Paraguaya en París: Dicha comisión quedó conformada por los siguientes empresarios e intelectuales: Ricardo Antonio Méndez Gonçalvez, presidente; Emilio Aceval, vicepresidente; Juan Gonçalvez, tesorero; Ricardo Brugada, secretario; y los vocales José Urdapilleta, Gastón Rivière, Cirilo Solalinde, Rafael Augusti, Ignacio Ibarra, Santiago Schaerer, Nicolás Anguo, Pedro B. Cassartelli, Guillermo Stewart y Antonio Pecci.

El país fue incorporado a la Exposición Universal gracias a la labor ejercida por su Consulado General en Burdeos, representado por el cónsul Max Winsweiler y el vicecónsul Joseph Aubian. Fueron ellos los encargados de reproducir en esa ciudad la obra que Alonso Criado había elaborado para la exposición barcelonesa. La traducción al francés fue obra de la R. Coussau \& F. Coustalat Imprimeurs-Éditeurs con el título La Rèpublique du Paraguay. Así consta en el catálogo oficial publicado en ese mismo año en París.

Para garantizar la presencia de recursos paraguayos en la Exposición Universal parisina, en Asunción trabajaron Carlos Rouvier en calidad de enviado extraordinario y ministro plenipotenciario de la República francesa en Buenos Aires, ${ }^{47}$ así como René Livio, por entonces cónsul de Francia establecido en la ciudad de Asunción. Ambos se dedicaron a difundir en Francia el valor de la yerba mate paraguaya, dando a conocer sus múltiples nombres: "Thé du Paraguay", "Thé des Missions", "Thé des Jésuites", "Ilex Paraguayensis", "Caa”, seguido de la frase: "le meilleur et le moinscher de tous les thés". ${ }^{48}$

La construcción del Pabellón de la República del Paraguay para la Exposición Universal francesa fue asumida por el cónsul de Paraguay en París, Charles Cadiot, quien también formó parte del jurado internacional, y quien dio a conocer un catálogo oficial de los objetos, personas, empresas e instituciones que recibieron medallas y reconocimientos en París. Junto a Cadiot actuó el resto de los cónsules del cuerpo diplomático paraguayo establecido en diversas localidades de Francia, entre ellos: Jules Desplanques, por la comuna francesa Cherbourg-Octeville del departamento de Manche ubicado en la región de Baja Normandía; Louis Lahaye, por la ciudad portuaria y comuna francesa llamada Dunkerque que está situada en el

\footnotetext{
${ }^{46}$ Pascal, Nicolas Bancel; Blanhard, Gilles Boëtsch, Éric Deroo, Sandrine Lemaire, Zoos humains. Au temps des exhibitions humaines; La Découverte-Poche;Paris; 2004.

47 Boletín Oficial de la República Argentina; Ministerio de Relaciones Exteriores y Culto; Buenos Aires; 1900.

48 Catálogue Officiel de la Repúblique du Paraguay, contenant les récompenses obtenudes a l'Exposition Universelle de 1889 a Paris. Imprimerie Typographique et Lithographique C. Lévy (rue Lafayette, 194); Paris; 1889; pp. 8-9.
}

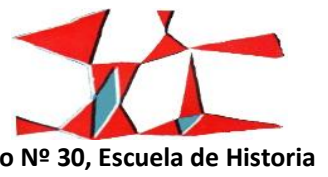




\section{MUJERES, SOCIEDAD Y ECONOMÍA DE LA REPÚBLICA DEL PARAGUAY}

departamento Norte de la región de Norte-Paso de Calais; G. Le Bourgeois, por la ciudad del noroeste de Francia llamada El Havre que está en el departamento de Sena Marítimo, y situada en la orilla derecha del estuario del río Sena a orillas del Canal de La Mancha; Alfred Ducreux, por la ciudad y comuna portuaria del sur de Francia llamada Marsella; David Bascle, por la ciudad francesa llamada Nantes que es capital del departamento de Loira Atlántico y de la región de países del Loira; Salomón de David del Vaille, por la ciudad francesa llamada Pau que se encuentra en el suroeste del país y es capital del departamento de los Pirineos Atlánticos en la región de Aquitania; Hammons Des Voisins, por la ciudad de Ruan (en francés, Rouen) ubicada al noroeste del país y es capital de la región de Alta Normandía y del departamento de Sena Marítimo; así como los cónsules León Aranda de Aaren y C. Nessler, ambos establecidos en Argelia, el territorio que desde el año 1830 había quedado en calidad de departamento de Francia, y que recién se liberó de este largo proceso colonizador en el año 1962.

Se presentó material de educación y documentos artísticos que recibieron el mayor número de medallas de oro. En primer lugar la colección etnográfica conformada por arcos, flechas, plumas y hachas de piedra, junto a la obra Mapas de Paraguay de Alonso Criado que llevaba el plano de la ciudad de Asunción y el croquis del Río de la Plata. En segundo lugar los álbumes de danzas nacionales, un buen número de fotografías sacadas en la capital del país, y la Carte Geogaphique du Paraguay del cartógrafo, historiador, coronel, arquitecto e ingeniero militar de origen húngaro Franz Wisner von Morgenstern, que el Gobierno de Paraguay hizo llegar a la capital francesa. En tercer lugar, unos 400 álbumes de música popular de Luis Cavedagui. Y en cuarto lugar unas 300 fotografías sobre la vida de campo que había elaborado el fotógrafo M. San Martín. Ese mismo grupo presentó el libro de Emmanuel de Bourgade La Dardye titulado La Paraguay moderne, avec avures et cartes que acababa de ser publicado por la editorial M. Plon \& Cía.

211

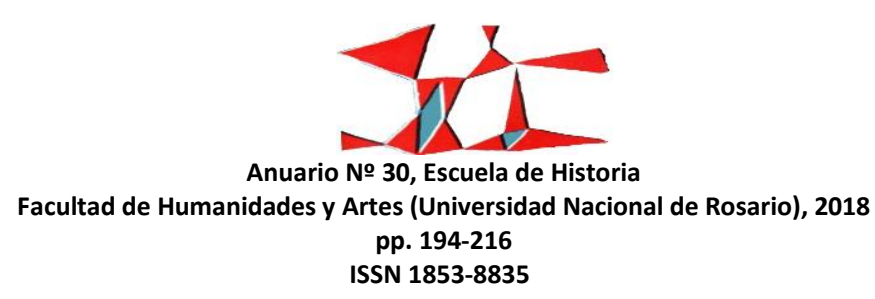




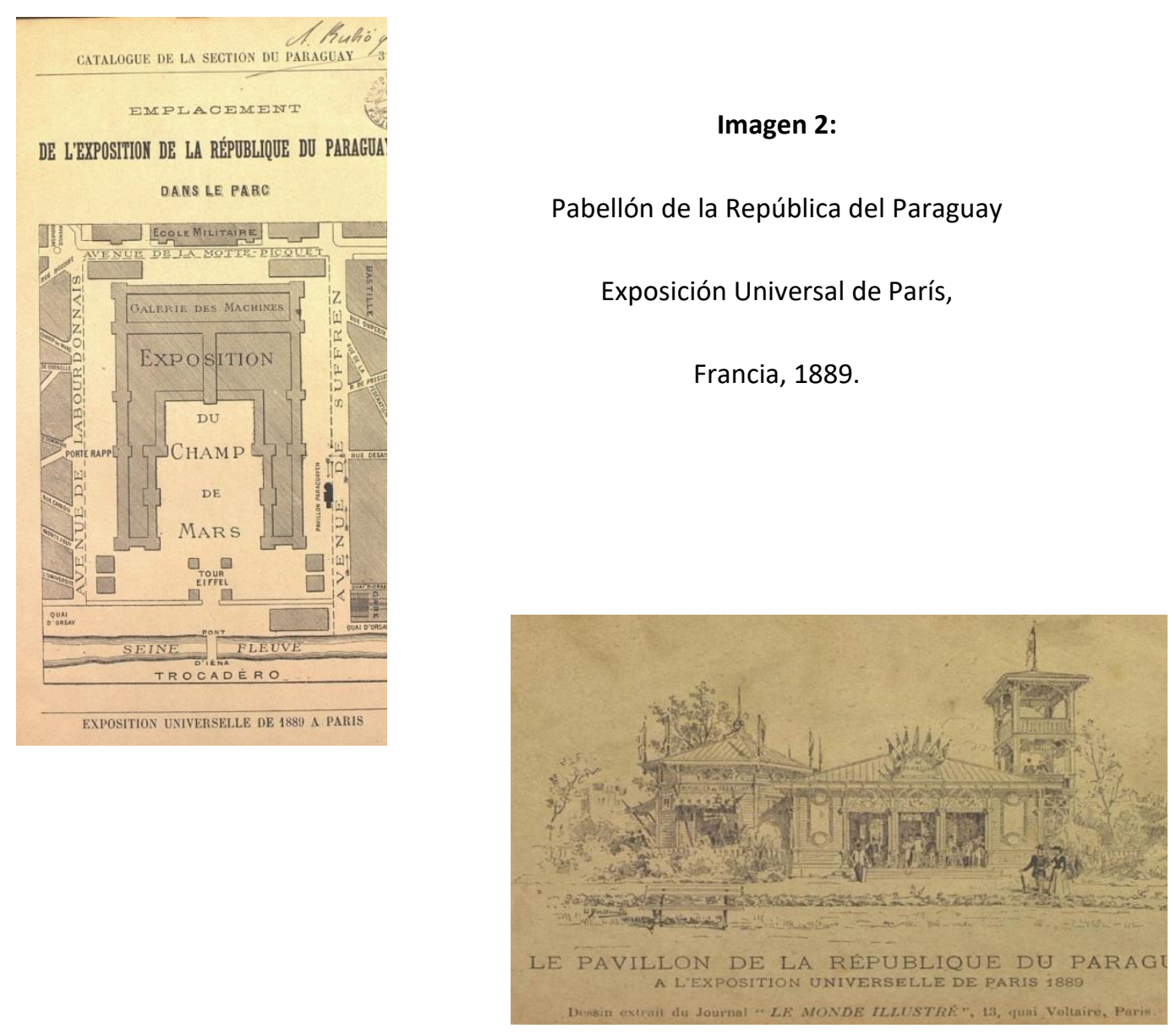

También se dieron a conocer muebles y accesorios, en especial productos de cerámica y ladrillos de diferente forma producidos por J. Guanes, Antonio Bugueta y la fábrica "Lapierre y Ladouce"; mosaicos, azulejos, aparatos de calefacción y sistemas de aclaramiento de "Manzano Hermanos"; productos de perfumería de M. Lagardia, E. Mendiondou y Juan Nerhot que se producían en Yaguarón, la localidad del noreste del Departamento de Paraguarí. A esto se sumaron las industrias extractivas que se encargaban de la madera, de las plantas medicinales, y del material colorante que se utilizaban para los curtidos. El catálogo identificó una enorme cantidad de maderas de bosque y materias colorantes, en especial las provenientes del espacio chaqueño, de Concepción y de la ribera oriental del río Paraguay. El Gobierno del Paraguay recibió el Grand Prix, y las medallas de oro y de plata por el tabaco y las fibras de Caraguatá. También fueron premiados “Montfort \& Kuntze” por semillas, cocodrilos y nutrias; E. Mendiondou, Luis Sá, Antonio Pirés, J. Boussiron, Lucas Papalucas y Antonio Gonçalves Pirez por cigarrillos y botellas de vino; A. Hassler por las fibras y cuerdas indígenas; y E. Mendiondou por la producción tabacalera. Y en el caso de productos alimenticios

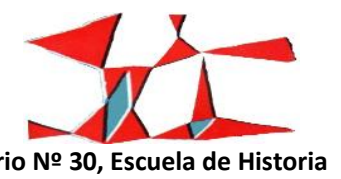




\section{MUJERES, SOCIEDAD Y ECONOMÍA DE LA REPÚBLICA DEL PARAGUAY}

fueron premiados los empresarios L. Van Strate, C. Duval, Agustín Cañete y “Pecci Hermanos y Cía." por la contribución de féculas de mandioca, botellas de sirop, y licores de anís, caña y ananás.

La Exposición Universal francesa premió y otorgó medallas y menciones a las mujeres paraguayas dedicadas a producir tejidos, prendas de vestir, accesorios y especialmente ñandutí. La participación femenina, sin duda, formó parte de este modelo de organización paraguaya después de la Guerra de la Triple Alianza. ${ }^{49}$ Hablamos de Joaquina Machaín, Lorenza Céspedes, Francisca Trigo, Petrona Acosta de Talavera, Encarnación Silva, Dolores Pedroso, las hermanas Elvira y Concepción Gill, Dolores Recalde, Benita Villalba, Martina C. Rivarola, Rosario Salalinde, Aurelia Machaín de Cartabio, Rita González y Carmen Gill de Cordal. Cumplió así con el desenvolvimiento de la República del Paraguay, y con la difusión del encaje de hilo, algodón o seda, representado por el ñandutí elaborado con agujas en Paraguay.

Los premios recibidos por estas mujeres (oro, plata, bronce y menciones especiales) siguieron así la propia conformación del ñandutí: pequeños cuadros, rectángulos y círculos que unían ese hilo y le daban forma, ofreciendo así una riquísima colección de encajes para un diverso público europeo, y ofreciendo un catálogo original en el que se registró el ñandutí con su nombre guaraní. Como ha señalado la especialista Bárbara Potthast, Paraguay es el país de la América Latina que más atención ha prestado al rol de las mujeres en su historia. Fue la devastadora Guerra contra la Triple Alianza la que provocó la obligación de las mujeres paraguayas de asumir la tarea de reconstruir el país, tanto a nivel social como económico. La participación de las mujeres no es sólo un mito. Poco a poco, según Potthast, se desarrolló un movimiento de mujeres trabajadoras, dedicadas a diversas áreas de producción, y que en elevado número dejaron la zona de campo para trasladarse y refugiarse en la ciudad de Asunción. En general, las mujeres se encargaron de gran parte de la economía de subsistencia y del pequeño comercio, y reconstruyeron la sociedad paraguaya afectada por la destrucción convirtiéndose en "jefas de familia". ${ }^{50}$

\footnotetext{
49 González, Natalicio; Proceso y formación de la cultura paraguaya; Guarania; Buenos Aires; 1948. González, Natalicio. El Paraguay eterno; Guarania; Asunción; 1935.

50 Potthast, Bárbara; “La mujer en la historia del Paraguay”, en Ignacio Telesca (ed.), Historia del Paraguay; Taurus; Asunción; 2010.
}

213

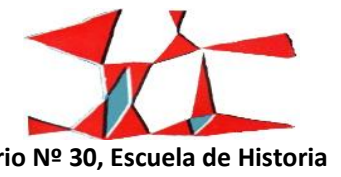

Facultad de Humanidades y Artes (Universidad Nacional de Rosario), 2018

pp. 194-216

ISSN 1853-8835 


\section{Reflexiones finales}

Una exposición supone un acto público de convocatoria en el que se exhiben colecciones de objetos de diversa temática. Por ejemplo, obras de arte, hallazgos de toda índole, instrumentos, maquetas y recursos que gozan de interés general, popular y masivo ante los objetivos manifestados por un determinado grupo o por la población. Siguiendo este principio podemos interpretar la presencia de objetos elaborados por mujeres paraguayas en las Exposiciones Universales y/o Internacionales que hemos analizado en este artículo. No sólo porque esas mujeres estaban dedicadas a producir mandioca, tabaco o caña, sino porque la tarea asumida fue dar a conocer el ñandutí (en español, tela de araña), es decir, un encaje de agujas tejido sobre bastidores en círculos radiales, bordando motivos geométricos o zoomorfos, y utilizando tanto el hilo blanco con vivos colores. ${ }^{51}$

Como sabemos, las exposiciones mundiales que dieron comienzo en 1851 y que llegaron a su cénit en 1933, estaban centradas en el comercio y en la presentación de avances tecnológicos. Las exposiciones universales o internacionales fueron la plataforma de demostración del estado de la técnica, de la ciencia y de la industria, así como del intercambio cultural. Desde entonces, las exposiciones se han concentrado en temas específicos dedicados a la cultura, las humanidades, el arte, los avances de la tecnología y la comunicación intercultural para el intercambio de innovación.

La participación de las mujeres paraguayas en las exposiciones mencionadas formó parte de las funciones ejercidas por estas actividades universales o internacionales. Dichas funciones pueden ser resumidas en simbólicas por su vinculación a la cultura y al valor ejercido por los objetos; en comercial por el valor de la mercadería en un mercado prefijado; documental por su ligazón con organismos e instituciones que nacen con la finalidad de exponer y difundir los conocimientos; y finalmente, estética, por el valor artístico de las obras.

Con esto en marcha, las mujeres paraguayas exportaron vestimenta, ornamentos religiosos, sombreros, abanicos, es decir, todo tipo de artículos ornamentales que pudiesen servir para dar a conocer la producción femenina de la República del Paraguay, y para demostrar su capacidad de llevar adelante el país. El ñandutí es considerado un símbolo: es la reina de toda la artesanía de la República del Paraguay, incluyendo

51 González, Gustavo; Ñandutí. Colección de la Biblioteca de Estudios Antropológicos; Ateneo Paraguayo; Asunción; 1967.

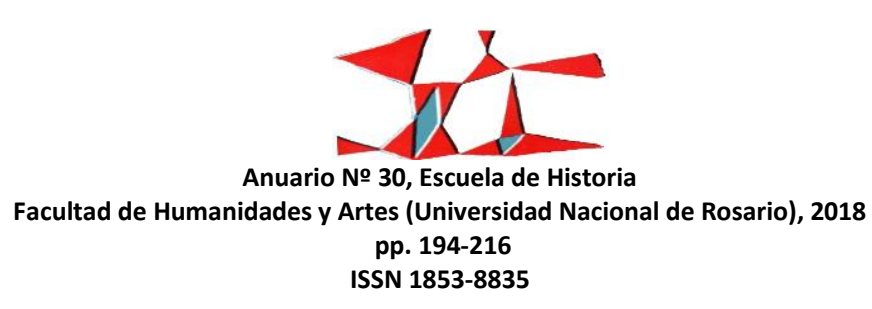




\section{MUJERES, SOCIEDAD Y ECONOMÍA DE LA REPÚBLICA DEL PARAGUAY}

los abanicos producidos con hilo de algodón y marfil, y es la "tela de araña" de sus mujeres como jefas de familia. ${ }^{52}$

Cabe recordar que el ñandutí posee su propia leyenda: dos bravos guerreros se disputaban el amor de una joven. Uno de ellos mató al contrincante que se había apropiado de un bellísimo tejido fabricado por las arañas, un encaje perfecto, para regalárselo a la mujer. Arrepentido, revela a su madre su crimen, y ésta decide estudiar cómo las arañas hilaban y dibujaban el maravilloso producto. Los varones, con sus armas, disputas, guerras, muerte. Las mujeres, con sus tejidos y sus esfuerzos por reconstruir, reparar, restañar heridas.

La tesis de que la jefatura femenina del hogar en Paraguay se apoya en las consecuencias de la Guerra de la Triple Alianza contra ese país. No es casual entonces que los hilos tejidos por las mujeres paraguayas fuesen expuestos públicamente en la Exposición Universal de Barcelona (1888) y en la de París (1889), con la doble intención de ofrecer la originalidad de la producción femenina al tiempo que la originalidad de los recursos naturales del país de postguerra. Las mujeres abastecedoras de alimentos en Paraguay también abastecieron a las Exposiciones Universales europeas, ofreciendo un negocio particular y estrictamente femenino. Dejar de lado el ñandutí, podía significar dejar de participar en el futuro de la República del Paraguay. Y de ahí el interés de las mujeres paraguayas que hemos mencionado en este artículo de ser registradas con sus propios nombres y apellidos personales, y no por su condición de casadas. Como ocurrió en esos difíciles años de posguerra, las mujeres labraron la tierra sin ayuda masculina, tejieron y produjeron el ñandutí, elaboraron hamacas para la vida familiar, y participaron formalmente en las Exposiciones Universales.

En 1950 fueron registrados 1.328.452 habitantes, duplicándose la población en 1982 para llegar a 3.023.092 personas, pero la imagen que acompaña al Paraguay es la de un país de mujeres cuya responsabilidad era buscar soluciones y resolver la situación social y demográfica paraguaya. ${ }^{53}$ Como en otras regiones marginales de Iberoamérica, las experiencias de sobreexplotación de recursos y la dramática alteración de los patrones territoriales y del paisaje que caracterizaban su inclusión a los mercados nacionales

\footnotetext{
52 Sanjurjo, Annick; Ñandutí, encaje paraguayo; Arandurã Editorial; Asunción-Paraguay; 2008.

53 Potthast, Bárbara; Paraíso de Mahoma o País de las Mujeres. El rol de la mujer y la familia en la sociedad paraguaya durante el siglo XIX; Instituto Cultural Paraguayo-Alemán; Asunción; 1996.
}

215

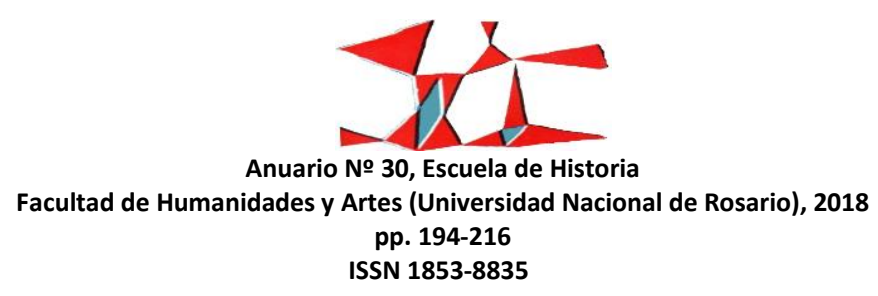


e internacionales, se vincularon de manera directa con las comunidades sobrevivientes. En el caso analizado en este artículo, con las mujeres paraguayas que se vieron obligadas a hacerse cargo del presente y del futuro de sus familias y del país, tema de gran importancia en el periodo de entreguerras. ${ }^{54}$ Reconocer este detalle hace que busquemos respuestas colectivas ante las nuevas realidades impuestas desde el exterior, en este caso por Exposiciones Universales ideadas en las ciudades más importantes de finales del siglo XIX: Barcelona y París. La República del Paraguay, en pleno proceso de recuperación demográfica y económica, formó parte de este diseño internacional.

${ }^{54}$ Morales Raya, Eva y Gabriela Dalla-Corte Caballero, Fabricio Vázquez Recalde y Arturo Landeros, La frontera argentino-paraguaya ante el espejo. Porosidad y paisaje del Gran Chaco y del Oriente de la República del Paraguay; Publicacions i Edicions UB; Barcelona: 2012. 